\title{
Analysis of Relevant Theories and Research Status of Financing Efficiency Chenggang $\mathrm{Li}^{1, \mathrm{a}}$ and Qing Liu ${ }^{1, \mathrm{~b},{ }^{*}}$ \\ Faculty of Finance, Guizhou University of Finance and Economics, Guiyang, 550025, China \\ a895977948@qq.com, b1138152399@qq.com
}

Keywords: Financing efficiency; Theory; Present situation; Influence factor

\begin{abstract}
The basic meaning of efficiency is the ratio of output and input. The efficiency of financing refers to the financing ability of each company in the market in financial activities. This paper first expounds the five related theories based on the financing efficiency, and explains the meaning and characteristics of each theory. Then it illustrates the domestic and foreign scholars' research and evaluation on the financing efficiency of new energy, culture industry, small and medium enterprises. Finally, this paper summarizes the influencing factors of financing efficiency from in domestic and foreign research literature.
\end{abstract}

\section{Introduction}

Efficiency has always been the core issue of economic research, and the low efficiency of corporate financing has always been a difficult problem in China. Enterprise financing is a key step in the development of an enterprise, and it is the basic condition to decide the operation state and expand the scale of an enterprise. The financing efficiency can be reflected from two aspects: one is the enterprise can promptly and effectively raise the required amount of money in the development process. This is closely related to financing mode and market conditions. How to use the lowest cost to obtain the biggest benefit of enterprise financing is the purpose of financing; the other is whether the funds obtained through the enterprise financing can be fully and effectively utilized. If the funds have not been fully utilized in the process of enterprise financing, it will lead to the cost waste, cause losses to the enterprise, and reduce to the financing efficiency.

This paper first explains some relevant theories of financing efficiency, including MM theory, Trade-off theory, Pecking Order Theory, Agency cost theory and Signaling theory. Then it introduces the review of domestic scholars and foreign literature on financing efficiency, expounds the methods for research scholars, such as data envelopment analysis (DEA), dynamic panel data model method. According to the data and the relationship between the various factors to obtain research results, and according to the results of the evaluation, we summed up the factors that affect the efficiency of financing. Due to the relatively large number of factors that affect the efficiency of financing, this paper summarizes the factors affecting the financing efficiency of scholars at domestic and abroad, and summarizes the future research direction of the financing efficiency.

\section{The theory of financing efficiency}

This paper mainly from the financing efficiency of five related theoretical analysis.

MM theory: Under certain conditions, the enterprise does not affect the total market value of the enterprise regardless of the debt financing or the equity capital financing. If the enterprises prefer debt financing, the proportion of debt rises correspondingly, the risk of the enterprise increases, and then reflects the price of the stock, the stock price will drop.

A proposition without corporate tax: When the corporate tax is not considered, the value of an enterprise is determined by its actual assets, rather than by the form of its acquisition. That is, the value of the firm has nothing to do with the capital structure. It also means that, with a suitable comprehensive capital cost rate for enterprise risk level, and make the EBIT (EBIT) capital, can determine the value of the enterprise. 
Proposition two without corporate tax: The cost of equity (KSL) of a company with liability is equal to the sum of the cost of equity (KSU) of a non indebted company in the same risk level and the risk premium. The risk premium is determined by the result of the cost of equity of companies without liability minus debt capital cost $(\mathrm{KD})$ ratio of debt company, then multiplied by the debt to equity ratio.

A proposition of corporate tax: The value of the company's liabilities equal to the sum of the same level of risk without negative and the value of the company liabilities plus tax benefits, tax benefits equal to the corporate tax rate multiplied by the amount of liabilities.

Proposition two with corporate tax: In the case of income tax, the cost of equity capital (KSL) of the indebted enterprise is equal to the cost of equity capital (KSU) of a non indebted enterprise in the same risk level and a certain risk return rate. The risk return rate is determined by without debt capital cost rate and liabilities of corporate debt capital cost rate (KD) and the difference of debt equity ratio.

Trade-off theory: The so-called trade off theory emphasizes the optimal capital structure when maximizing the enterprise value on the basis of balancing the tax benefit of debt interest and the cost of financial distress. The debt ratio at this point is the present value of the marginal value of the debt to tax income equal to the increase in the cost of the financial distress.

Pecking order theory: The pecking order theory assumes that the relaxation of MM theory of complete information, based on the asymmetric information theory, and considering the transaction cost, consider the negative equity financing will transfer the business information, and external financing to pay all costs, thus financing generally follow the internal financing, debt financing, equity financing such order.

Agency cost theory: The agency cost theory is formed through research agency cost and capital structure. Through theoretical analysis, the paper points out that the default cost of corporate debt is an increasing function of financial leverage coefficient; with the increase of corporate debt capital, the creditor's supervision costs will increase, the creditors will demand higher interest rates. The agency cost should be borne by the shareholders, and the debt ratio in the capital structure of the company will lead to the decrease of shareholder value. According to agency cost theory, the moderate capital structure of debt capital will increase shareholder's value.

Signaling theory: The research of western financial experts shows that under asymmetric information, there are three common signals that companies transmit internal information to the outside world: profit announcement, dividend declaration, financing announcement. Compared with the accounting manipulation of earnings, dividend announcement is a credible signal model. The application of signal transmission theory in the financial field began with Ross's research. He found that managers with a large number of high-quality investment opportunities could transmit information to potential investors through the choice of capital structure or dividend policy.

\section{Analysis of the current situation of financing efficiency}

Analysis of foreign research status. Alarcon (2007) [1] tested the effect of short-term debt on efficiency by a group of agricultural companies. First, the efficiency of the farm was obtained by using non-parametric methods. Then, in the second phase, the regression of the review is to use different kinds of explanatory variables, including financial ratios. The results show that there is a significant positive correlation between short-term liabilities and efficiency. The results of Wurgler (2000) [2] show that the efficiency of capital allocation is negatively correlated with the degree of state ownership economy, and it is positively correlated with the amount of specific information of domestic stock returns and the legal protection of minority shareholders. Sarkar, Singh (2010) [3] draws on the experiences of developing countries in terms of financing efficiency, and discusses the successful application in implementing energy efficiency solutions of various solutions of the key factors and financing tools. Through the case study, a review of all kinds of agency problems, these problems involves the identification, packaging, design and monitoring method. It is concluded that the knowledge sharing can lead to the energy efficiency of investment to expand.

Hayes (2011) [4] provides a set of tools, convenient, municipal utilities, and private banks to learn from the past experience, and provide effective energy efficiency programs. It can accelerate the pace of 
capital increase and the realization of energy conservation in residential and commercial buildings, obtained experience and lessons from the energy efficiency of the financing of the project. Chemmanur (2011) [5] uses the U.S. census bureau's longitudinal research database (LRD) to study some of the issues related to venture capital (VC) investment efficiency gains for private companies. Analysis shows that at each point of time the overall efficiency of venture capital (VC) support is higher than that of non-VC firms. While the overall efficiency gains generated by vc support are mainly due to improvement in sales, the efficiency gains of high reputation vc support companies also come from lower production costs. Finally, it proves that the VC's support and relevant efficiency gain have positive influence on the probability of successful export.

Analysis of domestic research status. In China, with the opening of financing market in all walks of life, the development is getting deeper. In order to provide better countermeasures and suggestions for the domestic enterprise financing market, the domestic scholars have conducted in-depth research and evaluation on the meaning of financing efficiency and influencing factors of efficiency .

J Cui (2014) [6] studied the influencing factors of the financing efficiency of unlisted small and medium-sized enterprises, using the dynamic factor panel data model method to analysis manufacturing enterprises more than 400 manufacturing enterprises of the financial data, and six groups of factors that affect financing efficiency are obtained, one of the biggest factors is the basic quality of the enterprise itself and the main business conditions. Corporate profitability, the size and liquidity of short-term foreign debt sources, the solvency of enterprises and the cost of commercial credit financing are relatively small. Y.X. Pan (2014) [7] for China's cultural and creative industries, starting from different financing mode, using data envelopment analysis (DEA) method, sample selection and index conducted an empirical study on financing efficiency, the results of the study show that the financing mode of China's cultural industry is relatively single, financing efficiency is low. Finally, according to the characteristics and basis of China's cultural industry itself, puts forward how to improve the efficiency of Financing Countermeasures and suggestions. P.P. Song (2015) [8] features the new energy industry, high risk, long term investment returns and so on, analyzes the selection of financing efficiency of solar photovoltaic and wind energy, the new energy industry, from the macro and micro level, the factors that influence financing efficiency are obtained. At the same time using the DEA model and the super efficiency model, from the financing efficiency of the dynamic and static analysis of the new energy industry, finally through the Tobit regression analysis obtained that the influence factors of financing efficiency has multiple.

Y Shen, J Zhao (2016) [9] through the study of the relationship between the proportion of food and beverage expenses and financing efficiency, using two stage instrumental variable method and dynamic panel analysis obtained the cost of food and drink is positively related to the amount of financing. The corruption of eating and drinking represents the corruption of social atmosphere, which indicates the lack of supervision mechanism and reduces the efficiency of investment. X.N. Wang (2016) [10] by the three stage DEA model on financing efficiency of small and medium industrial enterprises were evaluated, the results of the study indicate that with the increase in the number of years of business, the financing efficiency value of a ladder of growth, pure technical efficiency and the efficiency of financing is positively related to the financing efficiency of strategic emerging enterprises and the geographical location is located in the provincial Development Zone the enterprise is relatively high, the financing efficiency and non strategic emerging enterprises and foreign enterprises in the development zone is low.

\section{Influencing factors of financing efficiency}

There are many factors that affect the financing efficiency, the influencing factors of the financing efficiency analysis of the domestic and foreign scholars on the cultural industry, new energy, small and medium enterprises and other modules are different.

Wang (2006) [11] was put forward to evaluate the financing efficiency of the private enterprise model. The private enterprise financing efficiency evaluation index including financing cost, financing structure, management mechanism and other factors. By using the fuzzy comprehensive evaluation 
method (FCE) to evaluate the financing efficiency of private enterprises. Y Zhou(2013) [12] through a large number of empirical analysis, it is concluded that SME collective bonds and financing efficiency is closely related. Firstly, the DEA model is used to find out the relationship among the factors, and the multiple linear regression equation is established to analyze the influence of the indexes such as the correlation degree, the difference degree and the financial connection degree of the enterprise operation on the financing efficiency.

J Tang(2015) [13] analyzed the factors affecting the efficiency of cultural industry financing from macro and micro two aspects. From a macro point of view, first, it will be affected by laws, regulations and government policies, which means that the government should increase the support for the financing of cultural industries. Two is a good economic environment, including the level of economic development at home and abroad, the level of consumer spending, the import and export of cultural products. From the micro perspective, the capital structure of enterprises, including enterprise management ability, the growth ability of enterprises and so on. Y.M. Pan (2016) [14] discussion and research on the environmental protection industry financing problems, using the Tobit model from the enterprise financing, enterprise scale, enterprise quality, equity structure and macroeconomic variables on the operation conditions of the financing efficiency were investigated. The results show that bond financing is negatively related to corporate financing efficiency, while firm size, enterprise quality, ownership structure and macroeconomic performance are positively related to financing efficiency.

\section{Conclusions}

This paper reviews the related literature of financial efficiency on domestic and foreign scholars. It lists the current lack of evidence in this field and the direction of continuing research in the future. There are a lot of financing efficiency evaluation methods and empirical research methods. But there are also many problems, such as in the factor analysis of the factors influencing the financing efficiency is not comprehensive enough, or the selected data is not representative. The index model is too complex, and the analysis is also too complicated, so that its conclusion is confusion. Scholars can use more perfect methods in other fields of study, sample selection and the index can be more reasonable and more accurate for data analysis. At domestic and abroad on the cultural industry, environmental protection, new energy, new board and other studies are also obtained many representative results. But there are a lot of emerging industries is relatively small, such as big data industry. So we can take the big data industry financing efficiency and influencing factors as the next research direction. From the current situation of financing efficiency in our country, there are still many problems, such as high financing costs, non-standard mechanism, unstable market, etc., so we need to pay more attention to it, and make research results more targeted.

\section{Acknowledgements}

This paper is supported by Guizhou Soft Science Research Project "Study on the financing efficiency of big data industry and its influencing factors in Guizhou province" (Granted No.: Guizhou Science Cooperation Base[2017]1501).

\section{References}

[1] Alarcón S: Debt Financing and Efficiency in Agricultural Firms. Revista Espanola De Financiacion Y Contabilidad, Vol.37 (2007) No. 9436, p. 211-230.

[2] Wurgler J: Financial Markets and the Allocation Of Capital. Journal of Financial Economics, Vol. 58 (2000) No. 1-2, p.187-214.

[3] Sarkar A, Singh J: Financing Energy Efficiency in Developing Countries-Lessons Learned and Remaining Challenges. Energy Policy, Vol. 38 (2010) No. 10, p. 5560-5571. 
[4] Hayes S, Nadel $S$ and Granda C: What have we learned from Energy Efficiency Financing Problems?(Washinton, D.C. American September 2011). p.1-2

[5] Chemmanur T J, Krishnan K and Nandy D K: How does Venture Capital Financing Improve Efficiency in Private Firms? A Look Beneath the Surface. Review of Financial Studies, Vol. 24 (2011) No.12, p. 4037-4090.

[6] J Cui, H.Q. Hu and D.H Zhang: Research on Influence Factors of Unlisted Small and Medium-sized Enterprise Financing Efficiency -- Based on Empirical Evidence of Manufacturing Unlisted Small and Medium-sized Enterprises. Soft Science, Vol. 28 (2014) No.12, p. 84-88.

[7] Y.X. Pan, D.Y. Qiang and Y.P. Wei: The Research of Financing model and Its Efficiency for Cultural and Creative Industries. China Soft Science, (2014), No.3, p. 184-192.

[8] P.P. Song: The Study on Financing Efficiency of China's New Energy Industry and Its Influencing Factors. (MS.,China University of Mining and Technology,china 2015), p. 8.

[9] Y Shen, J.M. Zhao: The "gain" and "loss" of the cost of food and drink - Based on the investment and financing efficiency of listed companies. Financial Research, (2016) No.3, p.140-156.

[10]X.N. Wang, L Du and Q.T. Wang. Analysis of financing efficiency of small and medium sized enterprises based on three stage DEA model. Statistics and Decision Making, (2016), No.5, p.179-182.

[11] Wang P. An Evaluation Model on Financing Efficiency of Private Enterprises Based on FAHP. Commercial Research, (2006) No. 19, p. 114-117.

[12] Y Zhou, L Sha. An Empirical Study on the Influence of Key Characteristics of Small-and Medium-Enterprises Assemble Bond on Financing Efficiency - Hint on Optimize and promote SME assemble Bond Product. Journal of Engineering Management, Vol. 27 (2013) No.1, p.185-190.

[13] J Tang: Research on the Efficiency and Influence Factors of China's Listed Companies in Cultural Industry. (MS., Dongbei University of Finance and Economics,china 2016), p. 28.

[14] Y.M. Pang, Q.D. Yu and M.D. Zhu: A Study on Financing Efficiency Evaluation and Its Influencing Factors of Environmental Protection Industry in china. East China Economic Management, Vol. 30 (2016) No. 2, p.77-83. 